\title{
Increasing beta cell mass to treat diabetes mellitus
}

\author{
Shakila Sabir ${ }^{1, A, B, D, F}$, Ammara Saleem ${ }^{1, A, E, F}$, Muhammad Furqan Akhtar ${ }^{1, A, B, D, F}$, \\ Muhammad Saleem ${ }^{1, A, E, F}$, Moosa Raza ${ }^{2, A, E, F}$ \\ ${ }^{1}$ Faculty of Pharmaceutical Sciences, Government College University Faisalabad, Pakistan \\ ${ }^{2}$ Faculty of Pharmacy, University of Lahore, Pakistan \\ A - research concept and design; $\mathrm{B}$ - collection and/or assembly of data; $\mathrm{C}$ - data analysis and interpretation; \\ $\mathrm{D}$ - writing the article; $\mathrm{E}$ - critical revision of the article; $\mathrm{F}$ - final approval of the article
}

\section{Address for correspondence}

Muhammad Furqan Akhtar

E-mail: furgan.pharmacist@gmail.com

\section{Funding sources \\ None declared}

\section{Conflict of interest}

None declared

Received on March 8, 2017

Reviewed on May 17, 2017

Accepted on June 6, 2017

\begin{abstract}
Finding a radical cure for diabetes has reached paramount importance in medicine due to the widespread prevalence of the disease. A substantial reduction in insulin-secreting beta cells is evident in diabetes. The failure of cyclin-dependent kinases (CDKs) and cyclins to access the nucleus is responsible for quiescence or senescence in human and rodent beta cells. The augmentation of beta cell proliferation is supposed to reverse diabetes. This concept has inspired the discovery of newer drugs that encourage the proliferation of beta cells. Although itis a rational step towards a cure for diabetes, the differences in biochemical pathways in rodents and human beta cells pose difficulty in promoting the proliferation of human beta cells. Primarily, it is mandatory to clearly understand the intracellular pathways involved in the proliferation of beta cells so as to pave the way for therapeutic interventions. There are several intrinsic factors that trigger the proliferation of beta cells. Furthermore, it is also obvious that the early death of beta cells due to oxidative stress-related upregulation of pro-apoptotic genes also predisposes individuals to diabetes mellitus. Polyphenols, exendin 4, histone deacetylase inhibitors, glucagon-like peptide 1, phenyl pyruvic acid glucoside, and several flavonoids reduce the early apoptosis of beta cells partly through their role in the reduction of oxidative stress. A better understanding of intracellular pathways, the identification of specific mitogens, the induction of beta cell proliferation, and the inhibition of apoptosis may help us treat diabetes mellitus through an increase in beta cell mass.
\end{abstract}

Key words: diabetes mellitus, apoptosis, cell proliferation, rodent beta cells, human beta cells

DOI

10.17219/acem/74452

\section{Copyright}

Copyright by Author(s)

This is an article distributed under the terms of the

Creative Commons Attribution Non-Commercial License

(http://creativecommons.org/licenses/by-nc-nd/4.0/) 


\section{Introduction}

There is a pronounced rise in the prevalence of diabetes mellitus around the world. The number of diabetic patients is expected to rise to 300 million globally by $2030 .{ }^{1} \mathrm{Dia}-$ betes mellitus is a chronic metabolic abnormality characterized by persistent hyperglycemia. There are 2 main types of this disease: type 1 diabetes mellitus (DMT1) and type 2 diabetes mellitus (DMT2). DMT1 emerges from autoimmune reactions that result in the destruction of beta cells. ${ }^{2}$ DMT2 is a chronic ailment. An unhealthy diet and a sedentary lifestyle are the prime risk factors for DMT2. Other risk factors include obesity, reduced physical activity, and a genetic predisposition. ${ }^{3}$ DMT2 results from either a reduction in the secretion of and/or an emergence of resistance to insulin in the body. ${ }^{4}$ The autoimmune destruction of beta cells is accountable for the decline in insulin secretion. Beta cells are mostly found in the islet; however, they make up only about $2 \%$ of the pancreas. Beta cells are highly susceptible to hyperglycemia and become dysfunctional or even damaged by glucotoxicity. ${ }^{5}$

The damage to beta cells is further aggravated by a highfat diet, resulting in lipotoxicity. An autopsied pancreas model from DMT2 subjects revealed a 30\% decline in the number of beta cells in DMT2 individuals compared to healthy adults. ${ }^{6}$ The decrease in beta cells contributes to an increased death rate. Transplantation of the pancreas and beta cell replacement therapy have been investigated for the cure of DMT2. Although very promising, these procedures pose some serious obstacles and offer a limited scope of implementation. ${ }^{7}$ Another promising approach for the treatment of diabetes is to enhance the proliferation of beta cells through drugs. Table 1 shows the advantages and disadvantages of pancreas transplantation and beta cell replacement therapy.

Another approach in treating diabetes is to increase beta cell mass. However, the induction of beta cell proliferation was not possible in the past. Several studies have been carried out in the past decade, making it feasible thanks to an improved understanding of intracellular pathways. ${ }^{8}$ Adult human beta cells have an incredibly low rate of proliferation (about 1\%). There is a lack of specific mitogens

Table 1. Comparison of modern curative approaches to treating diabetes

\begin{tabular}{|l|l|}
\multicolumn{1}{|c|}{ Pancreatic islets transplant } & \multicolumn{1}{|c|}{ Replacement of beta cell } \\
\hline Advantages: & Advantages: \\
- independence of insulin & - independent of insulin \\
- decrease in secondary & - less invasive \\
complications & - abundant supply of beta cells \\
- prevention of hypoglycemia & - simple therapy \\
\hline Disadvantages: & Disadvantages: \\
- shortage of donors & - functionally immature beta cells \\
- auto-immunity & - poor response to glucose \\
- allo-immunity & - risk of cancer \\
- toxicity of immunosuppressive & - ethical considerations \\
drugs & - autoimmunity \\
& - poor quality control \\
\hline
\end{tabular}

that induce the proliferation of only beta cells without inducing generalized proliferation. The proliferation of certain growth factors may pose a risk of oncogenesis through the stimulation of undesired proliferation. ${ }^{9}$ In this review, we discuss the advancements and hindrances in the proliferation of beta cells. This review also highlights several factors that trigger the proliferation and inhibit the apoptosis of beta cells.

\section{Cell cycle cascade}

Human beta cells contain cyclin-dependent kinases (CDKs) and transcription factors (E2F). These molecules, like most adult cells, direct the entry of beta cells into the cell cycle. On the other hand, beta cells also exhibit several factors that resist the entry of beta cells into the cell cycle, such as CDK inhibitors and pocket proteins (i.e., p107, p130, and pRb). ${ }^{10,11}$ Mitogenic stimuli do not result in the proliferation of beta cells due to the inhibitory factors of the cell cycle. However, the overexpression of the positive factors directs the progression of beta cells in the cell cycle. ${ }^{12}$ The reversal of diabetes in diabetic mice was more pronounced in mice transplanted with human islets overexpressing cyclins and CDKs than those transplanted with normal human islets. ${ }^{13}$ It has also been found that the shRNA system of lentivirus silences cell cycle inhibitor p57KIP2, and thus allows entry into the cell cycle. ${ }^{8}$ Moreover, mutations in cell cycle inhibitor and tumor suppressor genes may render them inoperative and may culminate in the hyperplasia of endocrine cells. ${ }^{14}$

Cell cycle-associated molecules are usually located in the nucleus of cells. However, human beta cells, contain more G1 and S molecules in the cytoplasm rather than the nucleus, as observed by subcellular fractionation and immunocytochemistry studies. The overexpression and movement of cyclins, CDKs, and cell cycle inhibitors - and their movement inside and outside the nucleus contribute to the induction of beta cell replication, as confirmed by static immunocytochemistry and CDK-tagged live cells. Beta cells in rats also exhibit similar processes. For instance, CDK2 is abundantly found in the cytoplasm of non-proliferating rodent beta cells; however, it is located in the nucleus of proliferating insulinoma cells. ${ }^{10}$ Therefore, it can be inferred that the failure of CDKs and cyclins to access the nucleus is responsible for the quiescence or senescence in human and rodent beta cells.

\section{Intracellular signaling pathways}

Pancreatic beta cells have all the necessary cell cycle molecules that play a pivotal role in the proliferation of beta cells. However, the response of cell cycle machinery to mitogens is yet unclear. There is a need to further explore the exact cell signaling pathways so as to assess the reason for 
the nonproliferation of beta cells in response to growth factors and to some particular nutrients capable of inducing proliferation. ${ }^{15}$ This knowledge gap may be attributed to the complexity of methods of isolating and refining human beta cells and difficulties in their long-term preservation. The activation of protein kinase $\mathrm{B}$, protein kinase $\mathrm{C}$, or intracellular $\mathrm{Ca}^{2+}$ by gamma-aminobutyric acid or glucose induces the proliferation of human beta cells. ${ }^{16}$ The inhibition of glycogen synthase kinase 3 (GSK3) also induces proliferation. ${ }^{17}$ Some studies have revealed other signaling pathways involved in the proliferation of beta cells, such as the PI3K and IRS2 signaling pathways, activated by insulin or IGFs, and the MAP-kinase signaling pathway, activated by PDGF. ${ }^{18}$ Several efforts have been made to manipulate the signaling molecules for the induction of beta cell proliferation. However, the ultimate rate of proliferation was insignificant. For instance, lithium-induced inhibition of GSK3 $\beta$ increased the rate of proliferation up to threefold; however, the ultimate changes were insignificant, increasing from $0.17 \%$ to $0.71 \% .{ }^{17}$ On the whole, it can be assumed that the mitogenic signaling pathways are difficult to ameliorate and the currently-known mitogens exhibit only a weak effect on the activation of the cell cycle.

\section{Human and rodent beta cells}

Rodent and mammalian beta cells share the broad principles of beta cell biology. Rodent beta cells, therefore, have been extensively investigated. ${ }^{19}$ Human and rodent beta cells show marked differences in cell function and patterns of gene expression owing to diverse metabolic and nutritional demands. For instance, GLUT-2 is a chief glucose transporter in rodent beta cells; however, GLUT-1 performs this function in humans. ${ }^{20}$ Rodents exhibit 2 insulin genes - Ins1 and Ins 2 - whereas humans have only one insulin gene (INS). An absolute congenital loss of beta cells and, ultimately, neonatal diabetes arises due to mutations in NEUROG3 (which encodes the transcription factor neurogenin 3) in rodents. In humans, these mutations are linked to malabsorption and diarrhea due to damaged enteroendocrine cells. ${ }^{21}$ These mutations have variable effects on beta cell function and contribute to congenital diabetes and an altered response to hyperglycemia in adults. It is further revealed that NEUROG3 is not critical for the proliferation of human beta cells. ${ }^{22}$ MAFB (a transcription factor) is present in human beta cells and absent in rodents. ${ }^{23}$ Table 2 shows the differences in rodent and human beta cells due to which both species respond differently to different mitogens.

The islets of Langerhans house $80 \%$ of the beta cells in rodents and make up the islet core. However, these islets in humans contain only $50 \%$ beta cells scattered throughout the islets. There is also a significant difference in beta cell proliferation in both species. Beta cells proliferate at a maximum rate of $2 \%$ at any point throughout human life. ${ }^{24,25}$
Table 2. Differences in human and rodent beta cells

\begin{tabular}{|l|c|c|}
\multicolumn{1}{|c|}{ Parameter } & Human & Rodent \\
\hline Major glucose transporter & GLUT-1 & GLUT-2 \\
\hline Insulin gene & INS & Ins1, Ins2 \\
\hline NEUROG3 & non-essential & essential \\
\hline MAFB (transcription factor) & present & absent \\
\hline$\beta$ cells in islets & $50 \%$ & $80 \%$ \\
\hline Position of $\beta$ cells in islets & scattered & $\begin{array}{l}\text { make up } \\
\text { the core }\end{array}$ \\
\hline Proliferation at any point during life & $2 \%$ & $10-30 \%$ \\
\hline
\end{tabular}

GLUT-1 - glucose transporter type 1; GLUT-2 - glucose transporter type 2; INS - insulin gene; Ins1 - insulin 1 rodent gene; Ins2 - insulin 2 rodent gene; NEUROG 3 - encoding the transcription factor neurogenin-3; MAFB - musculoaponeurotic fibrosarcoma oncogene homolog b.

However, the peak rate of proliferation is considerably higher in rats and ranges from $10 \%$ to $30 \% .{ }^{26}$ Most studies employed beta cell originating from juvenile rodents 2 to 3 months of age for regeneration experiments. However, regeneration experiments in humans employed beta cells that were mainly obtained from individuals $40-50$ years old.

A large number of the interventions made in rats (such as obesity, high-fat diets, partial pancreatectomy, genetic models of insulin resistance, pregnancy, growth factors, mitogenic agents [such as placental lactogen, prolactin, glucose, hepatocyte growth factor, betatrophin, exendin 4, glucagon-like peptide (GLP1), epidermal growth factor(EGF), insulin-like growth factors (IGFs), osteocalcins, gastrin, and platelet-derived growth factor (PDGR)] and some other molecules, such as purinergic agonists, glucokinase activators, adenosine kinase inhibitors, and dihydropyridines) have been proven to be capable as strong proliferation activators. ${ }^{27}$ However, these interventions were ineffective in humans in inducing proliferation owing to the differences in age and other intrinsic factors. ${ }^{28}$ Consequently, there is a clear need to comprehend the biological differences in both species so that the findings in rat models may be implemented in the treatment of humans.

\section{Hindrances in the proliferation of beta cells}

The primary feature of human pancreatic beta cells is an incredibly small basal proliferation index (0.1-0.2\%) and a poor response to almost all mitogenic stimuli (0.3-0.5\%). Studies revealed that $99.9 \%$ of pancreatic beta cells are quiescent. However, the number of quiescent beta cells is reduced to $99.5 \%$ during mitogenic stimulation. Adult human beta cells exhibit resistance to mitogenic stimuli. Nevertheless, the proliferation rate during the early years of life is incredibly low (about $2 \%$ ) even when there is a maximum proliferation of beta cells. The reason behind the low proliferation rate of the beta cells is unclear. 
It has been speculated that the adult beta cells were replicatively senescent (a condition in which cells cannot enter the cell cycle due to a high activity of cell cycle inhibitory molecules like p16INK4a, p18INK4c, p27KIP1, p53, p57KIP2 p21CIP1, and others). ${ }^{29}$ This explanation is not satisfactory, as the cell cycle can be induced by an increased expression of cyclins and CDKs or by the activation of other positive signaling pathways. These cyclins and CDKs cannot get entry into the nucleus of these pancreatic beta cells, which keeps them in quiescence. ${ }^{10}$

An age-related alteration in the epigenetic makeup of the replicative machinery culminates in senescence. The loss of $E Z H 2$ (enhancer of zeste homolog 2) and BMI1 (a polycomb complex protein) results in an increased expression of p16INK4a and other CDK inhibitors. Age-related depletion of the receptors for mitogenic and platelet-derived growth factor may also render adult beta cells gradually unresponsive to mitogenic stimuli. ${ }^{30}$ However, the presence of GLP 1 and HGF receptors involved in the stimulation of mitogenic signaling pathways of rodent and adult human beta cells suggests the need to further investigate the age-related and species-specific deviations in intracellular signaling pathways. ${ }^{31}$

\section{Mitogens for proliferation}

A rational therapeutic approach to treating diabetes is the promotion of insulin secretion through encouraging the proliferation of beta cells. A key challenge in promoting the proliferation of beta cells is to enhance their proliferation without increasing the generalized proliferation rate. ${ }^{19}$ It is evident from the previous studies that glucose has the potential to promote human and rodent beta cell proliferation under both in vitro and in vivo conditions. ${ }^{32}$ Glucokinase (GK) metabolizes glucose after its uptake into beta cells. It is the rate-limiting step of glycolysis. Glycolysis increases ATP concentration, which results in the closure of ATP-sensitive potassium channels (KATP) and causes a depolarization of the cell membrane. This depolarization results in the opening of voltage gated $\mathrm{Ca}^{2+}$ channels, and an ultimate increase in intracellular $\mathrm{Ca}^{2+}$ level triggers the exocytosis of insulin. Several studies have demonstrated that glucose-induced proliferation also occurs through this glucose-triggered insulin secretion pathway. Several studies have shown the link between glucokinase activation and beta cell proliferation. This renders glucokinase an appealing target for interventions to promote proliferation. ${ }^{33}$ Glucokinase activators exhibit a conservation of beta cell mass in rat models. ${ }^{34}$ Intracellular $\mathrm{Ca}^{2+}$ functions as a physiological regulator of the glucose-triggered insulin secretion pathway. It is also evident that dihydropyridine derivatives activate $\mathrm{L}$-type $\mathrm{Ca}^{2+}$ channels to promote the proliferation of beta cells. ${ }^{35}$ Beta cells also proliferate due to calcium-dependent phosphatase calcineurin, the nuclear factor of the activated T cell (NFAT) pathway. Table 3
Table 3. List of the chemicals that enhance the proliferation rate and reduce beta cell apoptosis resulting in the conservation of beta cell mass

\begin{tabular}{|c|c|c|}
\hline $\begin{array}{c}\text { Nature } \\
\text { of chemicals }\end{array}$ & $\begin{array}{l}\text { Proliferation } \\
\text { enhancer }\end{array}$ & $\begin{array}{l}\text { Apoptosis } \\
\text { inhibitors }\end{array}$ \\
\hline \multirow{4}{*}{ Small molecules } & GKA & \multirow{4}{*}{ N/A } \\
\hline & calcium signaling & \\
\hline & adenosine signaling & \\
\hline & WS6 & \\
\hline \multirow{4}{*}{ Hormones } & insulin & insulin \\
\hline & lactogen signaling & estrogen \\
\hline & incretin & incretin \\
\hline & betatrophin & triiodothyronine \\
\hline \multirow{4}{*}{ Phytochemicals } & \multirow{4}{*}{ N/A } & resveratrol \\
\hline & & PPAG \\
\hline & & flavonoids \\
\hline & & $\begin{array}{l}\text { glutathione peroxidase } \\
\text { mimetics }\end{array}$ \\
\hline
\end{tabular}

GKA - glucokinase activator; N/A - not applicable; WS6 - compound name with molecular formula C29H31F3N6O3; PPAG - phenylpropenoic acid.

lists the molecules involved in the conservation of beta cell mass through an enhancement of the proliferation rate and a reduction in the apoptosis of beta cells.

A nonspecific adenosine receptor agonist (NECA) was identified as a potent enhancer of beta cell proliferation through a zebra fish whole-body screen in regenerating conditions. NECA acts through the beta cell surface adenosine receptor $\mathrm{A} 2 \alpha$ and its proliferative and hypoglycemic action has been demonstrated in diabetic mice. These observations suggest a possible link between glucose metabolism and adenosine signaling via a glucose-induced increase in intracellular ATP concentration that, in turn, enhances beta cell proliferation in a paracrine fashion. ${ }^{36}$ ATP depletion in dying cells exhibits adenosine as a stress signal. This signal enhances beta cell proliferation following tissue damage. ${ }^{37}$ It is also evident from the studies that the inhibition of nuclear adenosine kinase activity may induce beta cell proliferation selectively in rodent diabetic models. ${ }^{38}$ WS6 effectively stimulates beta cell proliferation in both rodent and human islets dose-dependently. Additionally, there is a variety of growth factors and hormones that increase proliferation, such as incretins, insulin, parathyroid hormone related protein (PTHRP), PDGF, IGFs, EGF, and hepatocyte growth factor (HGF). ${ }^{39}$ Gastric inhibitory polypeptide (GIP) and GLP1 are secreted from the gut and reduce the blood glucose level efficiently through multiple signaling pathways, including beta cell proliferation. GLP1 receptor agonists are extensively used for the management of diabetes and increase the secretion of insulin by binding to their receptors on beta cells. ${ }^{40}$

GLP1 receptor agonists and DPP4 inhibitors exhibit beta cell proliferation in rodent models. However, there is no evidence that either of these would be effective in diabetic patients. Moreover, it has also been found that incretin 
therapy may induce pathological lesions with a high risk of oncogenicity. ${ }^{41}$ Beta cells proliferate as a result of increased insulin demand in conditions such as pregnancy, obesity, and insulin resistance. These conditions are helpful in the identification of several hormones involved in beta cell mass expansion. The concentration of placental lactogen and prolactin increases during pregnancy and these hormones are involved in the proliferation of beta cells. ${ }^{42}$ It has been established that the lactogen-induced proliferation of beta cells is accomplished through the production of the neurotransmitter serotonin in the islet tissues. ${ }^{43}$ Consequently, modulation in serotonin signaling may be helpful in controlling hyperglycemia. In addition, prolactin stimulates the proliferation of beta cells by suppressing menin levels. ${ }^{44}$ Menin inhibitors have also been developed and evaluated for their potential to induce proliferation. It is further necessary to identify and investigate the related drugs to enhance the proliferation of beta cells.

\section{Inhibition of beta cell apoptosis}

Apoptosis is the hallmark of beta cell loss and plays a pivotal role in the progression of DMT2. ${ }^{45} \mathrm{~A}$ high fat diet contributes mainly to beta cell apoptosis owing to oxidative stress associated with glucotoxicity and lipotoxicity. Studies have revealed the upregulation of pro-apoptotic genes in response to oxidative stress resulting in cell death. ${ }^{46}$ Several compounds causing elevated glucose uptake by the muscle and fat tissues also exerted positive effects on beta cell survival. Likewise, some compounds with antioxidant potential also proved helpful in the prevention of apoptosis. ${ }^{47}$

Polyphenols present in natural products may be used as anti-apoptotic agents due to their high antioxidant potential. Flavonoids (genistein, anthocyanins, and epigallocatechin gallate) and other polyphenolic compounds (like stilbene and resveratrol) prevent the apoptosis of beta cells through a reduction of oxidative stress. These compounds also exhibit a potential to modulate anti-apoptotic and proapoptotic proteins present in the beta cells. ${ }^{48}$ It has been found that phenyl pyruvic acid glucoside (PPAG) protects patients from hyperglycemia and increases the beta cell mass in rodents. ${ }^{49}$

PPAG and several flavonoids have antioxidant potential. These compounds also cause an upregulation of Bcl-2 which prevents apoptosis. ${ }^{50}$ Inflammation, along with gluco-lipotoxicity, plays a vital role in beta cell death in DMT2. Interleukin 1 (IL-1) signaling is found to be involved in the pathogenesis of DMT2. ${ }^{51}$ Resveratrol prevents the IL-1ß-induced dysfunction of pancreatic beta cells. ${ }^{52}$

Histone deacetylase inhibitors (HDACi) can be utilized in the management of diabetes as these chemicals suppress IL-1ß signaling. HDACi also block cytokine-induced apoptosis in streptozotocin-induced diabetes. ${ }^{53}$ Likewise, exendin-4 protects cytokine-induced beta cell apoptosis. ${ }^{54}$
Additionally, exendin- 4 also diminishes gene expression in response to stress in the endoplasmic reticulum of partially pancreatectomized rats. ${ }^{55}$ GLP1 may expand beta cell mass in leptin receptor-deficient mice through a reduction of oxidative stress. ${ }^{56}$

GLP1 also exhibits an anti-apoptotic effect in isolated human islets. ${ }^{57}$ Numerous rodent models reported a higher susceptibility to developing diabetes in male animals than in their female counterparts. ${ }^{58}$ Therefore, it is suggested that gonadal hormones also play a significant role in the development of the disease. Estrogen-receptors (ERs) expressed in human and rodent beta cells include ER $\alpha, E R ß$, and $G$ protein-coupled ERs. These receptors also contribute to beta cell survival. It is evident that estrogen reduces oxidative stress and lipotoxicity-associated loss of beta cells. ${ }^{58,59}$ Additionally, estrogen also protects beta cells against pro-inflammatory cytokines. Triiodothyronine (T3), a thyroid hormone, also exhibits an anti-apoptotic effect through the modulation of pro- and anti-apoptotic factors like Bcl-XL, Bcl-2, Bad, Bax, and caspase $3 .{ }^{60}$

\section{Conclusions}

On the basis of this discussion, it can be concluded that physiological stimuli may enhance the proliferation of beta cells in order to conserve beta cell mass. Several small molecules have shown the potential to induce proliferation, which warrants further investigation in order to explore their exact mechanism of action and to optimize them. Numerous phytochemicals that are capable of reducing the apoptosis of beta cells to conserve beta cell function have also been introduced. Several mitogens increase the proliferation of beta cells in rodents; they are, however, unable to induce proliferation in human beta cells due to various intrinsic and nutritional factors. It is necessary to further develop and select more appropriate experimental models to test mitogens for beta cell proliferation. Likewise, it is also necessary to develop an appropriate non-invasive method to assess beta cell mass.

\section{References}

1. Kahn SE, Cooper ME, Del Prato S. Pathophysiology and treatment of type 2 diabetes: Perspectives on the past, present, and future. Lancet. 2014;383(9922):1068-1083.

2. Roizen JD, Bradfield JP, Hakonarson H. Progress in understanding type 1 diabetes through its genetic overlap with other autoimmune diseases. Curr Diabetes Rep. 2015;15(11):1-7.

3. Dupuis J, Langenberg C, Prokopenko I, et al. New genetic loci implicated in fasting glucose homeostasis and their impact on type 2 diabetes risk. Nature Genet. 2010;42(2):105-116.

4. Marques-Vidal P, Bastardot F, Kanel R, et al. Association between circulating cytokine levels, diabetes and insulin resistance in a population-based sample (CoLaus study). J Clin Endocrinol. 2013;78(2): 232-241.

5. Weir GC, Bonner-Weir S. Islet $\beta$ cell mass in diabetes and how it relates to function, birth, and death. Ann NY Acad Sci. 2013;1281(1):92-105. 
6. Rahier J, Guiot Y, Goebbels R, et al. Pancreatic $\beta$-cell mass in European subjects with type 2 diabetes. Diabet Obes Metab. 2008;10(s4): 32-42.

7. Niclauss N, Meier R, Bedat B, et al. Beta-cell replacement: Pancreas and islet cell transplantation. In: Novelties in Diabetes. Switzerland: Karger Publishers; 2016:146-162.

8. Avrahami D, Li C, Yu M, et al. Targeting the cell cycle inhibitor p57 Kip2 promotes adult human $\beta$ cell replication. J Clin Invest. 2014;124(2): 660-664.

9. Bernal-Mizrachi E, Kulkarni RN, Scott DK, et al. Human $\beta$-cell proliferation and intracellular signaling part 2: Still driving in the dark without a road map. Diabetes. 2014;63(3):819-831.

10. Fiaschi-Taesch NM, Kleinberger JW, Salim FG, et al. Human pancreatic $\beta$-cell G1/S molecule cell cycle atlas. Diabetes. 2013;62(7):2450-2459.

11. Fiaschi-Taesch NM, Kleinberger JW, Salim FG, et al. Cytoplasmic-nuclear trafficking of G1/S cell cycle molecules and adult human $\beta$-cell replication a revised model of human $\beta$-cell G1/S control. Diabetes. 2013;62(7):2460-2470.

12. Lavine JA, Raess PW, Davis DB, et al. Overexpression of pre-pro-cholecystokinin stimulates $\beta$-cell proliferation in mouse and human islets with retention of islet function. Mol Endocrinol. 2008;22(12):2716-2728.

13. Fiaschi-Taesch NM, Salim F, Kleinberger J, et al. Induction of human $\beta$-cell proliferation and engraftment using a single $\mathrm{G} 1 / \mathrm{S}$ regulatory molecule, CDK6. Diabetes. 2010;59(8):1926-1936.

14. Agarwal SK, Mateo CM, Marx SJ. Rare germline mutations in cyclindependent kinase inhibitor genes in multiple endocrine neoplasia type 1 and related states. J Clin Endocrinol Metabol. 2009;94(5): 1826-1834.

15. Kulkarni RN, Mizrachi EB, Ocana AG, et al. Human $\beta$-cell proliferation and intracellular signaling. Diabetes. 2012;61(9):2205-2213.

16. Demozay D, Tsunekawa S, Briaud I, et al. Specific glucose-induced control of insulin receptor substrate-2 expression is mediated via $\mathrm{Ca}^{2+}$-dependent calcineurin/NFAT signaling in primary pancreatic islet $\beta$-cells. Diabetes. 2011;60(11):2892-2902.

17. Liu H, Remedi MS, Pappan KL, et al. Glycogen synthase kinase-3 and mammalian target of rapamycin pathways contribute to DNA synthesis, cell cycle progression, and proliferation in human islets. Diabetes. 2009;58(3):663-672.

18. Rhodes CJ, White MF, Leahy JL, et al. Direct autocrine action of insulin on $\beta$-cells: Does it make physiological sense? Diabetes. 2013;62(7): 2157-2163.

19. Conrad E, Stein R, Hunter CS. Revealing transcription factors during human pancreatic $\beta$ cell development. Trend Endocrinol Metab. 2014;25(8):407-414

20. De Vos A, Heimberg H, Quartier $\mathrm{E}$, et al. Human and rat beta cells differ in glucose transporter but not in glucokinase gene expression. J Clin Invest. 1995;96(5):2489.

21. Gradwohl G, Dierich A, LeMeur M, et al. Neurogenin 3 is required for the development of the four endocrine cell lineages of the pancreas. Proceed Nat Acad of Sci. 2000;97(4):1607-1611.

22. Rubio-Cabezas O, Codner E, Flanagan SE, et al. Neurogenin 3 is important but not essential for pancreatic islet development in humans. Diabetologia. 2014;57(11):2421-2424.

23. Dai $C$, Brissova $M$, Hang $Y$, et al. Islet-enriched gene expression and glucose-induced insulin secretion in human and mouse islets. Diabetologia. 2012;55(3):707-718.

24. Gregg BE, Moore PC, Demozay D, et al. Formation of a human $\beta$-cell population within pancreatic islets is set early in life. J Clin Endocrinol Met. 2012;97(9):3197-3206.

25. Mezza T, Muscogiuri G, Sorice GP, et al. Insulin resistance alters islet morphology in nondiabetic humans. Diabetes. 2014;63(3):994-1007.

26. Teta M, Long SY, Wartschow LM, et al. Very slow turnover of $\beta$-cells in aged adult mice. Diabetes. 2005;54(9):2557-2567.

27. Campbell JE, Drucker DJ. Pharmacology, physiology, and mechanisms of incretin hormone action. Cell Metabol. 2013;17(6):819-837.

28. Griffin KJ, Thompson PA, Gottschalk M, et al. Combination therapy with sitagliptin and lansoprazole in patients with recent-onset type 1 diabetes (REPAIR-T1D): 12-month results of a multicentre, randomised, placebo-controlled, phase 2 trial. Lancet Diabetes Endocrinol. 2014;2(9):710-718.

29. Tchkonia T, Zhu Y, Van Deursen J, et al. Cellular senescence and the senescent secretory phenotype: Therapeutic opportunities. J Clin Invest. 2013;123(3):966-972.
30. Chen H, Gu X, Liu Y, et al. PDGF signaling controls age-dependent proliferation in pancreatic [bgr]-cells. Nature. 2011;478(7369): 349-355.

31. Baggio LL, Drucker DJ. Biology of incretins: GLP-1 and GIP. Gastroenterology. 2007;132(6):2131-2157.

32. Alonso LC, Yokoe T, Zhang P, et al. Glucose infusion in mice a new model to induce $\beta$-cell replication. Diabetes. 2007;56(7):1792-1801.

33. Porat S, Weinberg-Corem N, Tornovsky-Babaey S, et al. Control of pancreatic $\beta$ cell regeneration by glucose metabolism. Cell Metab. 2011;13(4):440-449.

34. Futamura M, Yao J, Li X, et al. Chronic treatment with a glucokinase activator delays the onset of hyperglycaemia and preserves beta cell mass in the Zucker diabetic fatty rat. Diabetologia. 2012;55(4):1071-1080.

35. Wang W, Walker JR, Wang $X$, et al. Identification of small-molecule inducers of pancreatic $\beta$-cell expansion. Proceed Nat Acad Sci. 2009; 106(5):1427-1432.

36. Andersson $\mathrm{O}$, Adams BA, Yoo D, et al. Adenosine signaling promotes regeneration of pancreatic $\beta$ cells in vivo. Cell Metab. 2012;15(6):885-894.

37. Xu X, D'Hoker J, Stange $G$, et al. $\beta$ cells can be generated from endogenous progenitors in injured adult mouse pancreas. Cell. 2008;132(2): 197-207.

38. Annes JP, Ryu JH, Lam K, et al. Adenosine kinase inhibition selectively promotes rodent and porcine islet $\beta$-cell replication. Proceed Nat Acad Sci. 2012;109(10):3915-3920.

39. Vasavada RC, Gonzalez-Pertusa JA, Fujinaka Y, et al. Growth factors and beta cell replication. Int J Biochem Cell Biol. 2006;38(5):931-950.

40. Ding L, Gysemans $C$, Mathieu C. $\beta$-cell differentiation and regeneration in type 1 diabetes. Diabetes Obes Metab. 2013;15(3):98-104.

41. Butler AE, Campbell-Thompson M, Gurlo T, et al. Marked expansion of exocrine and endocrine pancreas with incretin therapy in humans with increased exocrine pancreas dysplasia and the potential for glucagon-producing neuroendocrine tumors. Diabetes. 2013;62(7): 2595-2604.

42. Brelje TC, Bhagroo NV, Stout LE, et al. Beneficial effects of lipids and prolactin on insulin secretion and $\beta$-cell proliferation: A role for lipids in the adaptation of islets to pregnancy. J Endocrinol. 2008;197(2): 265-276.

43. Kim H, Toyofuku Y, Lynn FC, et al. Serotonin regulates pancreatic beta cell mass during pregnancy. Nat Med. 2010;16(7):804-808.

44. Karnik SK, Chen H, McLean GW, et al. Menin controls growth of pancreatic ß-cells in pregnant mice and promotes gestational diabetes mellitus. Science. 2007;318(5851):806-809.

45. Donath MY, Ehses JA, Maedler K, et al. Mechanisms of $\beta$-cell death in type 2 diabetes. Diabetes. 2005;54(Suppl 2):108-113.

46. Cunha DA, Igoillo-Esteve M, Gurzov EN, et al. Death protein 5 and p53-upregulated modulator of apoptosis mediate the endoplasmic reticulum stress-mitochondrial dialog triggering lipotoxic rodent and human $\beta$-cell apoptosis. Diabetes. 2012;61(11):2763-2775.

47. Mahadevan J, Parazzoli S, Oseid E, et al. Ebselen treatment prevents islet apoptosis, maintains intranuclear Pdx-1 and MafA levels, and preserves $\beta$-cell mass and function in ZDF rats. Diabetes. 2013;62(10): 3582-3588.

48. Gilbert ER, Liu D. Anti-diabetic functions of soy isoflavone genistein: Mechanisms underlying its effects on pancreatic $\beta$-cell function. Food Funct. 2013;4(2):200-212.

49. Mathijs I, Cunha DA, Himpe E, et al. Phenylpropenoic acid glucoside augments pancreatic beta cell mass in high-fat diet-fed mice and protects beta cells from ER stress-induced apoptosis. Mol Nutr Food Res. 2014;58(10):1980-1990.

50. Wang C, Guan Y, Yang J. Cytokines in the progression of pancreatic $\beta$-cell dysfunction. Int J Endocrinol. 2010;13:34-42

51. Banerjee M, Saxena M. Interleukin-1 (IL-1) family of cytokines: Role in type 2 diabetes. Clini Chim Acta. 2012;413(15):1163-1170.

52. Ku CR, Lee HJ, Kim SK, et al. Resveratrol prevents streptozotocin-induced diabetes by inhibiting the apoptosis of pancreatic $\beta$-cell and the cleavage of poly (ADP-ribose) polymerase. Endocr J. 2012;59(2): 103-109.

53. Lewis EC, Blaabjerg L, Storling J, et al. The oral histone deacetylase inhibitor ITF2357 reduces cytokines and protects islet beta cells in vivo and in vitro. Mol Med. 2011;17:369-377.

54. Liu X-H, Remedi MS, Pappan KL, et al. Exendin-4 protects murine MIN6 pancreatic $\beta$-cells from interleukin-1 $\beta$-induced apoptosis via the NF-KB pathway. J Endocrinol Invest. 2013;36(10):803-811. 
55. Kwon DY, Kim YS, Ahn IS, et al. Exendin-4 potentiates insulinotropic action partly via increasing beta-cell proliferation and neogenesis and decreasing apoptosis in association with the attenuation of endoplasmic reticulum stress in islets of diabetic rats. J Pharmacol Sci. 2009;111(4):361-371.

56. Shimoda M, Kanda Y, Hamamoto $S$, et al. The human glucagon-like peptide-1 analogue liraglutide preserves pancreatic beta cells via regulation of cell kinetics and suppression of oxidative and endoplasmic reticulum stress in a mouse model of diabetes. Diabetologia. 2011;54(5):1098-1108.

57. Farilla L, Bulotta A, Hirshberg B, et al. Glucagon-like peptide 1 inhibits cell apoptosis and improves glucose responsiveness of freshly isolated human islets. Endocrinol. 2003;144(12):5149-5158.
58. Tiano JP, Mauvais-Jarvis F. Importance of oestrogen receptors to preserve functional $\beta$-cell mass in diabetes. Nat Rev Endocrinol. 2012; 8(6):342-351.

59. Le-May C, Chu K, Hu M, et al. Estrogens protect pancreatic $\beta$-cells from apoptosis and prevent insulin-deficient diabetes mellitus in mice. Proc Nat Acad Sci. 2006;103(24):9232-9237.

60. Verga FC, Panacchia L, Bucci B, et al. 3,5,3'-triiodothyronine (T3) is a survival factor for pancreatic $\beta$-cells undergoing apoptosis. $J$ Cell Physiol. 2006;206(2):309-321. 